\title{
Aspectos inmunológicos de las enfermedades malignas
}

\author{
Dr. Jorge Vildósola San Martín*
}

Fn los últimos años se ha despertado gran interés en los aspectos jumunológicos de las enferniedades malignas. La literatura pertinento ha trecido en forma exponcncial desde 1970 hista la fecha, tanto en el aspecto experimental como en terreno clinico (1).

La sosprecha de que los organismos vivos intentan de alguna mancra dcfenderse de un proceso maligno ha encontrarlo apoyo en nu. meroso: hechos experimentales y clínicos (2). En la tabla No 1 se resumen algunas evidencias clinicas de probable reacción inmunológica a los tumores malignos.

Tabla No 1

EVIDEXCIAS CIINICAS DE REACCION INMUNOLOGIGA EY LOS TUMORES HUMANOS

1. Incidencia por edactes.

2. Sobrevida prolongata espontinea.

3. Mayom sobrevita en pacientes con Lefensa antitumoral demostrata.

4. Regresión espontánea.

1. Regresión de netástasis.

6. Esrudio postruntem.

7. Fìilconcia histológica.

8. Respucsta a la quimioterapia.

9. Crecirriento irregular cu distintos sitios.

10. Mayor frocuencia de tumores en estatos de inmunodeficiencia (Congénita o adquirida).

En primer lugar, tenemos la incidencia por elades de los diversos tumorcs malignos. Lat miyor frecuencia en las personas de mayor Rio.

- Departamento de Pediatría. Hospital Roberto del Rev, Chilena de Pediatría, Vol. 47, No 1, 1976 edad, cstaria en relación con lá disminución de las detensas inmunológicas generales del ser humano que se comprueban en las etapas tarclías de la vida, a lo cual no sería ajeno la progresiva atrofia del sisterna linfático con la clad. Claro estát que también podrian invocarse otras razones, tal como la mayor exposición a agentes cancerigenos tanto en calidad como en tiempo.

La variabilidad de la sobrevida de pacientes con un mismo tipo de tumor, también hablaria en fayor de una mayor o menor efectivilad de los mecanismos inmunológicos capaces de controlar una malignidad. No es excepcional la observación ale tumores cuyo creci. miento se detiene por períodos prolongados.

Otra observación que viene en apoyo de la importancia de los mecanismos inmunológicos en la defensa antitumoral es la siguiente: si los pacientes demuestran inmunodeficiencia, medida por su inhabilidad para adquirir sensibilidad cuténea al dinitroclorobenceno, los tumores crecen más rápidamente que en los pacientes que no exhiben tal deficiencia (3).

La regresión espontánéa demostrada en algunos tumores, tai como el neuroblastoma de la infancia, apoya fuertemente el control inmunológico del crecimiento tumoral (4), uunque esta no es la única razón que podría invocarse. E1 agotamiento intrínseco de la capacidacl proliferativa (madurativa o no madurativa) es otra posibilidad que hay que tomat en cuenta.

La regresión de algunas metástasis después de la extirpación del tumor primitivo no es 
rara, y este hecho estaria $e n$ relación con la aparición y/o incremento de los factores desbloqueadores que sigue a la extirpación del tumor principal. Este cambio en la situción inmunoiógica del pacientc, de un estado de "progresión" a uno de "regresión", sería res. ponsable de las regresiones le las metristasis después de la eliminación del tumor primitivo (5).

El estudio postmórtem de pacientes ha revelado la existencia de una mayor proporción de tumores (la mayoría microscópicos) que su inciclencia clinica. Por ejemplo, eI neuroblastoma, presenta una prevalencia necrópsica unas 40 veces más alta que su incidencia clínica. Esio indicaría que normalmen. te se desarroltan y regresan tumores con más frecucncia que los que progresan hacia la detectación clínica. Hallazgos similares se han comprobado para el carcinotru tiroideo y el carcinoma prostático (5).

Descle el campo de la histopatología vicne una observación que apoyatía la tesis de un control inmunc de los tumores. $S_{\mathrm{e}}$ ha comprobado que aquellos neoplasmas que tienen marcadir infiltracion linfocitariu, sobeviven mayor tiempo y progresan en forma más Ienta $(6)$.

Otro hecho que apoyaría la importancia de los factores inmunológicos frente a los tumores malignos reside en la observación del comportaniento del linfoma de Burkitt y a cotiocarcinona frente a la quimioterapia (5). En estos casos, bista el cmplea de un solo agente quimioterápico y a dosis convencionales, para proxlucir desaparición dramática del umor. Se cree que las defensas del huésped eliminarían dichos tumores, con la ayuda de una quimioterapia a todas luces insuticiento para controlar por sí sola un tumor maligno.

E] crecimiento irregular de distintos depó. sitos de células malignas con regresión de algunos de cllos a la par del crecimionto de otros, hablatia en lavor de procesos locales cle inmunidad anticancer cuyo establecimiento es inpsrfectamente conocirlo (5).

Рог último, la mayor incidencia de tumores malignos en pacientes con inmunodeficiencia, ya sea ésta congénita o adquirida, es probablimente el mejor argumento para pensar en uma estreclia ralación entre cáncer y autoinmuniclad (7).

En la tabla No 2 vemos una lista de síndromes, que tienen deficiencia inmunológrica primaria. En todos ellos la frecuencia de tumores sobrepasa en mucho la frecuencia de tumores en la población general igual quc en la inmunodeficiencia iatrogénica provocada por la quimioterapia anticancerosa y los inmunosuprcsores de trasplantes y enfermedades

Tabla Na?

TIPOS DE MALIGNIDADES REPORTADAS EN INMUNODEIICIENCIAS PRIMARIAS

\begin{tabular}{|c|c|c|c|c|c|c|c|c|}
\hline \multirow[t]{2}{*}{ Situdrome } & \multicolumn{2}{|c|}{ Defect o* } & \multirow{2}{*}{$\begin{array}{l}\text { Epi- } \\
\text { telial }\end{array}$} & \multirow{2}{*}{$\begin{array}{l}\text { Linfo- } \\
\text { reticular }\end{array}$} & \multirow{2}{*}{$\begin{array}{l}\text { Porcentajes } \\
\text { Leu- } \\
\text { cemia }\end{array}$} & \multirow{2}{*}{$\begin{array}{l}\text { Mesen- } \\
\text { quima }\end{array}$} & \multirow[t]{2}{*}{ S.N.G. } & \multirow{2}{*}{$\begin{array}{l}\text { Total } \\
\text { casos }\end{array}$} \\
\hline & $L B$ & $7 . T$ & & & & & & \\
\hline $\begin{array}{l}\text { Wiskott-Alerich } \\
\text { Inmunadeficiencia }\end{array}$ & $\mathbf{x}$ & $\mathrm{x}$ & 0 & 81 & 9 & 5 & 5 & 21 \\
\hline $\begin{array}{l}\text { cong. ligada aI sexo } \\
\text { Inmunodeficiencia }\end{array}$ & $\mathbf{x}$ & & 0 & 16 & 67 & 0 & 16 & 6 \\
\hline combinada sisténica & $\mathbf{x}$ & $x$ & 0 & 57 & 43 & 0 & 0 & 7 \\
\hline Ataxia-tclangectasia & $\mathbf{X}$ & $\mathrm{x}$ & 1) & 65 & 16 & 4 & 4 & 46 \\
\hline $\begin{array}{l}\text { Inmunodeficiencia } \\
\text { variable común }\end{array}$ & $\mathrm{X}$ & $\mathbf{x}$ & $3 R$ & 41 & 34 & 3 & 3 & 34 \\
\hline Deficiencia en IgA & $\mathbf{x}$ & & $7 \vec{a}$ & 25 & 0 & 0 & 0 & 4 \\
\hline TOTAL & & & $18 \%$ & $57 \%$ & $175 \%$ & $3,5 \%$ & $4 \%$ & 118 casos \\
\hline
\end{tabular}

-LB: linfocito $\mathbf{B}$.

LT: Linfacito $\boldsymbol{T}$ 
autoinmunes $(8,9), \Lambda$ este respecto convienc recordar eI hecho de que muchos agentes cancerigenos tales como agentes químicos (metilcolantreno) y diversos virus oncogénicos son a la vez inmunosupresores a la pat de oncogénicos $(10,11)$.

En torno a este tema y en enfermedades en las que se ha aclaracto el factor en deficiencia se han comprobado hechos curiosos y relevantes: En la agammaglobulinemia ligada al sexo (Tipo Brutton) con deficiencia en linfocitos $\mathbf{B}$ (déficit en la formación de anticuerpos inmunoglobulínicos) la mayor incidencia es de tumores tipo linfoma-leucemia, no observándose tumores epiteliales. En la deficiencia de IgA (inmunoglobulina esencial para la defonsa de las mucosas de los tractos respiratorio y gastrointestinal), predominan las malignidades epitelialcs de estos sistemas, sin que se observe leucemia y mesenquimomas. En las deficiencias combinaklas, de linfocitos B y $\mathrm{T}$, se observan tanto epiteliomas malignos como tunores linforreticulares y leucemias, con porcentajes variables según el síndrome de que se trate (escasos epiteliomas en el WiskottAldrich y en la inmunodeficiencia combinarda sistémica severa; alto porcentaje en la ataxia telangectasia y en la inmunodeficiencia variable común). La inmunodeficiencia en linfocitos $T$ pura, se caractetiza por la escase sobrerida de los pacientes por lo que no es corricnte que sc pesquisen tumores malignos.

Uno de Ios grandes problemas en oncologia radica en el conocimiento imperfecto del com. portamiento fisiopatológico de las células tumorales. En la Fig. No 1 vemos consignados

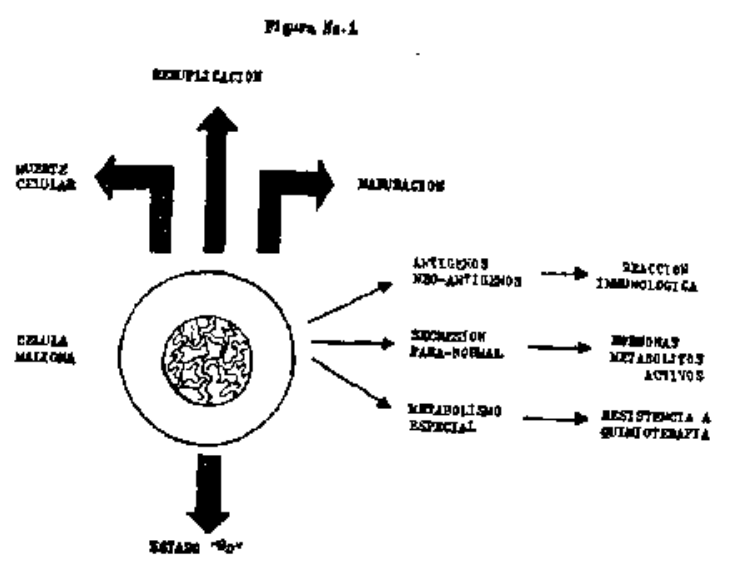

algunos hechos relevantes en torno a la evo. lución y metabolismo de una célula neoplásica. Se debe destancar que la célula cancerosa posec antígenos propios tanto de superficie (en la membrana celular) como en el citoplasma y núcleo. Son estos antigenos propios los que provocan una respuesta inmune en el huésped, la que en la mayor purte de los casos es sorteada y sobrepasada por la actividad neoplásica. En la actividad secretoria paranormal se deben consignar también, aparte de las substancias con actividad méabólica y hormo-símil, la actividad vasoformadora incitada por el tumor y la sccreción de los antígenos en el medio circundante y a los Itumores generales clel luuésped, Fn el rubro del metabolismo cspecial sc ponc enfasis en uno de los problemas unás descsperantcs desile el punto de vista terapéutico, ya que lit extrema variabilidad de el, permite a la célula maligna resistir la acción de los agentes quimioterapéuticos (Resistencia medicamentosa).

La presencia de antígenos en la célula maligna es esencial, como ya se expresó, para la provocación de una respuesta inmanitaria dcl huéspecl. Parece tazonable inletir que aquellas células neoplásicas con escaso poder inmunogénico tienen mayor posibilidad de sobrevivir y progrestr hasta matar al enfermo. E1 heclo de que los anlígenos puedan ser secretados al medio circundante permite al organismo crear delensas inmunológicas al tumor, pero por otro lado, los antígenos solubies antago. nizan dichas defensas, bloqueando las acciones inmunes tanto celulares como humorales. Del equilibrio o desequilibrio de esta interrelación dependerát la progresión o la regresión cle un tumor maligno.

En la tabla $\mathrm{N}^{\circ} 3$ se consignan algunas de las viuiedades de antígenos que pueden poseer las celulas cancerosas.

Como puede observarse, son múltiples las varielades de antígenos que poseen los tumores, entre los cuales figuran también los que tienen las células normales, tales como los antigenos de histocompatibilidad que se ponen en evidencia por medio de trasplantes.

Los antígenos onco-fetales son principal. mentc de tres tipos: 1). Antigeno carcino-embrionario (CEA), 2). Las fetoproteínas (Alfa, 


\section{ANTIGENOS EN CELULAS TUMORALES}

1. Antigenos de histocompalibilidad.

(HiL-A, Transplante) .

\section{Antigenos onco-fetales}

a. Carcino-embrionario (CEA) .

b. Feto-protcinas: alfa-fetoproteina.

gama-fetoproteína.

alfa-2-H-fctoptoteina.

beta-S-Ictoproteina.

sulfo-glico-proteina fetal.

c. Fosfatasa alcaline placentaria.

3. Antlgenos intuctsos por vinus

a. Linforna de Burkitt.

b. Carcinoma nasofaringco.

(p. ej.: Antigeno de membrana (MA): antígeno capsular virico (VCA): antigeno temprano (EA); antígeno soluble (SA).

4. Antigenos de origen indeterminado

(Especificos, inducidos por virus, inducción química).

a. Melanoma.

b. Neuroblastoma.

c. Encéfalo.

d. Tracto urinario '(dif. de CE.S) .

e. Cáncer mamario.

f. Leucemia-Linfoma.

g. Sarcomas.

\section{Cripto-antigenos}

En la membrana celular, expuestos en la destrucción parcial de Ja membrana.

6. Antigenos especificos vle tunor (TSA)

Neo-antigenos?

beta, gamma, alfa-2 y sulfoglicoproteina) y 3). Fosfatasa alcalina tipo placentario. Todos estos antigenos son de muy buena tolerancia ya que cxcepcionalmente forman anticuerpos (12). Se argumenta que su presencia se debe a un proceso de desdiferenciación celular hacia etapas embrionarias de la vida que sufren las células neoplásicas. La comprobación de su presencia serviria sobre todo como un medio de diagnóstico y de seguimiento evolutivo (3). No son exclusivos de procesos malignos ya que también se les encuentra en proceso inflamatorios crónicos del tubo digestivo y del aparato respiratorio (13) .

Los antigenos inducidos por virus son cono- cidos e importantes en dos procesos cancerosos: el linfoma de Burkitt $y$ el carcinoma nasofaringeo, en cuyas células se encuentran antígenos virales (de la variedad herpes) y reoantígenos originados por el virus (14).

En el cuarto rubro tenemos los antígenos de origen indeterminado. Algunos autores piensan que son específicos de tumor (neoantígenos verdaderos) y otros, que estarían estrecha. mente relacionados con algún tipo de virus oncogénico. Tal sería el caso de los sarcomas de origen mesenquimático, de los neuroblastomas, de leucemias y linfomas, etc. (13).

Los criptoantigenos serían aquéllos localizados profundamente en la membrana celular y que se ponclrían en evidencia cuantlo la pared celular es parcialmente digerida por la acción de enzimos (por ej. neuraminidasa). Su exteriorización permitiría al huésped rcaccionar vigorosamente en forme inmunológica al tumor, lo cual ha encontracto apoyo en he. chos experimentales (15).

Los antigenos especificos de tumor (neadn. tigenos verdaderos) corresponderian según al; origen indeterminato, $y$ aunque on últim: instancia pudieran dcberse a la acción de agentes oncogénicos cono virus o/y substancias Guímicas, su presencia le da a las células neoplásicas, el corácter de célulats "diferentes" de las células nowiales.

Ciuàles serían los mecanismos inmunológicos de destrucción de células tumorales? Estos serían de varios lipos (Tabla No 4):

Tabla No 4

MECANISMOS DE DESTRLCCION DE CELLILAS TUMORALES (INMUNOLOGICOS)

1. Destrucción por anticherpos más complemento.

2. Destrucción por anticuerpos linfocito-dependientes.

3. Dustrucción por linfocitos.

4. Destrucción por linfocitutoxinas

5. Destrucción por macróagos.

1. Destrucción por anticucrpos más comple. mentos: Los anticuexpos inducidos por los antigenos de la membran: celular, se adhieren a la célula cancerosa, y con la ayuda del complemento se proctuce la destrucción de la cólu- 
Ja malignat. Este fenómeno se utiliza preferentcmente como un método de diagnóstico in vitro de la inmunidad antitumoral. In vivo no está claro el papel de los anticuerpos antitumor ya que según las evidencias acumuladas, su papel en la destrucción de malignidades no parece ser relevante cuando no contradictorio. Mucios turoores crecen y progresan en presencia de tasas altas de anticuerpos anticancerosos (If).

2. Desirncción por anticuerpos linforito- dependientes: En esta eventualidad los anticuerpos (innunoglobulinas) se fijan a los linfocitos, por la fracción Fc de las inmunoglobulinas, y serían estos linfocitos "armados" Ios encargados cle la destrucción tumoral (17).

3. Destruccion por linfocilos: Este parece ser in vivo un mecanismo importante en el combate de un organismo contra la malignidad. Esta acción es utilizada como prueba in vitro de efectividad antitumoral en aquellas prueban que exploran la inmunidad celular anticancerosa. La actividad citotóxica de los linfocitos (linfocitos $T$ ) se la ha encontrado predominantemente en una subpoblación lin. focitaria, los cuales son más grandes, con más pironinofilia y más radiorresistentes que la mayoria de los linfocitos (18).

4. Destrucción por linfociloloxinas: Los linfocitos estimulados secretarian un factor no especffico, tóxico, que destruirían las células malignas. No se está seguro que este mecanismo tenga un rol biológico serio $(19,20)$.

5. Destrucción por mactófagos: Este parece ser un mecanismo efectivo de destruoción tumoral. La interacción de linfocitos y macrófagos se ha demostrado compleja e interesante. Por un 1ado, los linfocitos $T$ estimulados por antígenos liberan un factor que tomados por los macrófagos y probablemente condicionado por éste, interacciona, al ser liberado por los macrofagos, con los linfocitos B y los condicionan para la formación de anticuerpos específicos. Por otro Iado, una variedad de anticuerpos antitumorales (anticuerpo citofílicos) son tomados por los macrófagos, transformándolos en macrófagos "armados" o "agresores" (21, 22, 29).
Como puede observarse, el combate del huésped contra un tumor maligno requiere una estrecha colaboración de elementos celulares (linfocitos $T$ con sus subpoblaciones "heIper" y supresores, linfocitos B, y macrofagos) (24), e inmunoglobulinas y complemen. to (25). Esta interacción es variada y compleja, y la efectividad de los mecanismos dependerá de la adecuada sincronización de los hechos expuestos (Fig. No 2).

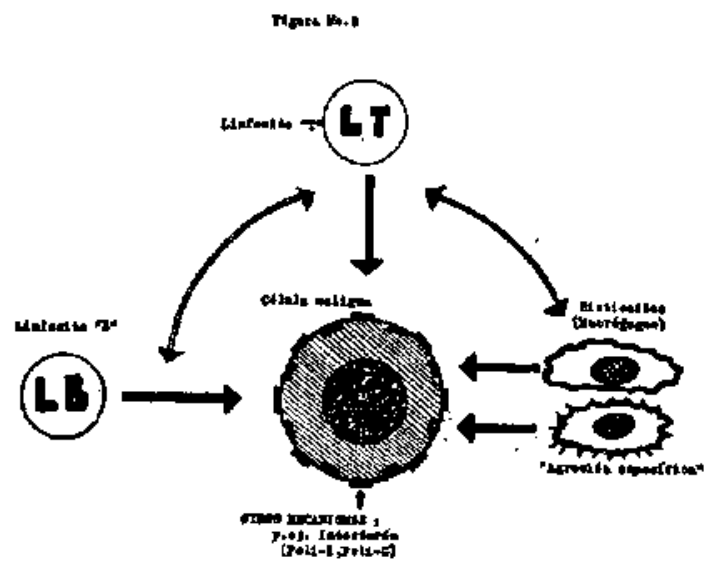

Una de las paradojas de la inmunologfa del cáncer consisté en que pese a que es posible demostrar que la mayor parte de los tumores poseen antigenos y que éstos provocan una respuesta de inmunidad, el tumor escapa a este mecanismo, crece progresivamente y termina viteriormente con la vida del paciente.

Para explicar esta situación se han propuesto diversas teorias, algunas de éstas no salen del terreno estrictamente teórico (Tabla 5) .

Tabla No 5

MECANISMO DE EVASION DEL TUMOR A IA VIGILANCIA INMLNOLOGICA

1. Factores bloqueadores

2. Tolerancia intu unológica

3. Atrapamiento linfocitario

4. Mocituación

5. Inhübición no especifica

6. Kinćtica celular

7. Defectos en poder itununogénico

I. Factores bloqueadores: Múltiples son las evidencias de que un tumor maligno es capaz de antagonizar la acción de los anticuerpos y los elementos celulares de defensa del huésped. Se pensó inicialmente en la presencia 
de factores protcicos que favorecerían directimente el crecimiento del tumor, pero investi. gaciones más finas y sofisticaclas parecen demostrar que los factores bloqueadores son propiamente los antígenos tumoralcs o cotnplejos antigeno-anticuexpos, que actúan neutralizando Ios anticuerpos tumorales, ya sea formando dichos complejos, bloqueando los linfocitos citotóxicos o recubriendo las células neoplásicas impidiendo la acción destructora de los linfocitos o/y macrofagos $(20,27,08$, 29, 30). En la mayoría de los tumores que crecen rápidamente se ha clemostrado la presencia de factores bloqueadores o favorecedores del crecimiento (estado de progresión). Si cl tumor es eliminado, persisten los anticuerpos antitumorales sin factores bloqueadores. El suero de cstos pacicnues recibe el nombre de sueros clesbloqueadores o regresores, ya que en las prucbas in vítro potencian la destrucción de las células malignas.

2. Tolcrancia inmunológica: Según estat teoría los antigenos iumorales inducirian en el huésped un estado de tolerancia que impediria una respuesta inmune aclecuada. Experimentalunente esta teroría encuentra escaso apoya $\langle 31\rangle$.

3. Atrapamicnto injoctario: Es un curioso becho con comprobación experimental. Los antigenos secretados por el tumor retionen en el ganglio linfático regional a $\operatorname{los}$ linfocitos potencialmente cirotóxicos. Esto se demostró en ratas portadoras de sarcomas inducidos con benzopireno, cuyos ganglios linfáticos tributarios del tumor no liberaban inmunoblastos hacia el conducto torácico. Si el tumor era eliminado, se apreciaba una gran cantidad de inmunoblastos en la linfa del conducto torúcioo, fonómeno que cesaba si sc reimplantaba el tumor (32).

4. Modulación: Otro fenómeno curioso que ocurre en la interactión de anticuerpos y antigenos de superficie celular. Ante la presencia de anticuerpos específicos, los antigenos de membrana celular no son detectados, porque se produce una reorganización intrínseca de conformación de la pared de la membrana con replicgue hacia el interior celular de los locus antigénicos. Los antigenos se expresan nuevamente cuando el anticuerpo deja de actuar. De estr materta, los anticuerpos antitumorales transformarían las células malignas en células a] marcntemernte desprovistas de antigenos, escapando por lo tanto a la acción destructiva dc los anticuerpos y le los elementos celulares especificamente agresores $(39,34)$.

5. Inhibición no especificn: Los agentes quimicos y virales cancerigenos producen supresión de jits respuestas inmunológicas. La supresión es en todo caso parcial y generalmente se requieren dosis más altas que las necesarias prita inducir tumor. No parece ser un mecanisno operante en cancerología humana (31) .

6. Kinética celular: Esta teoría trata de $\mathrm{ex}$ plicar el crecimiento neoplásico en base al rapicio crocimiento y reduplicación celular, que sobrepasaría cuantitativamente la acción contraria de los anticuerpos o elementos celulares. Sin embargo, la mayoria de los tumores crece rclativamente en forma lenta, como para que este mecanismo sea válido clínicamente (31) (5). Una variante de esta teoría scría aquella que explicaría el crecimiento celular continuo por la existencia de células troncalcs antigénicamente neutras (“null”" cells) y por cllo inatacables inmunológicanente.

7. Defecto en el poder inmunogénico: Esta teoría se basa en la marcada desorganización celular de los tumores malignos con marcada anormalidad de la interacción celular. Este defecto en la asociación intercklular se extendería también a la relación entre célula malig. na y linfucito, la cual no seria optima para controlar la malignidad, por la falla en esiablecer adhesiones y contactos estables. Esto claría como resultado una aparente pobre inmunogenicidad. El hecho de que células neo. plásicas tratadas con neuraminidasa (una bi(Irolasi cicida) adquieren un aumento dramático de la inmunogenicidad, hablaria en favor de la inportancia de la modificación del contenido en ácido siálico de Ios determinantes antigénicos, ya que los resíduos de ácido siálico en los grupos prostéticos glicoproteicos son de gran importancia en la anormal conducta social de las células neoplásicas (15). Está aún por dilucidarse, por otro laclo, el papel 
cle las chalonas y las antichalonas (moléculas celulares especificas de tejido que controlan la proliferacion celular por sus acciones antimitóticas y mitogénicas, respectivamente), factores muy importantes en la relación cćlula a célula de un tejido determinado $(35,36,37$. 38).

\section{INMUNOTERAPIA}

Los ha!lazgos expcrimentales y clínicos en torno da inmunología del cáncer, han llevado al convencimiento da que es posible influir en la respuesta inmunológica de los pacientes, aunque los métodos en uso son controvertidos y las bases fisiopatológicas de ellos, imperfcrtamente conocidas. Pese a todo, los ensayos clínicos de inmunotcrapiz se han visto incre. mentaclo en gran númcro y variedad.

Los métodos utilizados se pueden resunir en: generales, locales; acivos y pasivos específicos y no específicos. Tabla No 6.

a. Inmunoterapia gencral activa espectica:

Consiste en la alministración de cclulas tumorales, generalmente por via intramuscular, ya seãn irradiadas, tratadas con formalina o sometidas a la acción de enzimás (por ej. neuraminiclasa). La idea general es aumentar el poder inmunogénico (humoral o/y celular) por medio de la inyección de dosis altas de antígenos. Este tipo de inmunoterapia ha logrado resultados variables y muy difícil de evaluar, por cuanto ha sido generalmente usada en pacicntes con cáncer avanzado y en otras condiciones que hacen imposibles las comparaciones adecuadas sobre todo si no sc toma en cuenta la situación inmunológica del paciente previa o actual de los pacientes. En todo caso, los mejores resultados inparentes se han conseguido en el melanoma maligno $(39)$, y en las leucemias agudas $(10,41)$.

\section{b. Innunoterapia generul, activa, no} cespecisica:

Consiste principalmente en el uso de coadyu. valutes, es decir complejos hiológicos lipoglicoproteicos, generalmente de origen bacteriano, que al ser inyectados, producen un enérgico extímulo general de las defensas del hućsped, sabre todo por la exaltación del sistema

$T_{\text {abla }} \mathrm{N}^{t /} 6$

INMU!NOTERAPJA

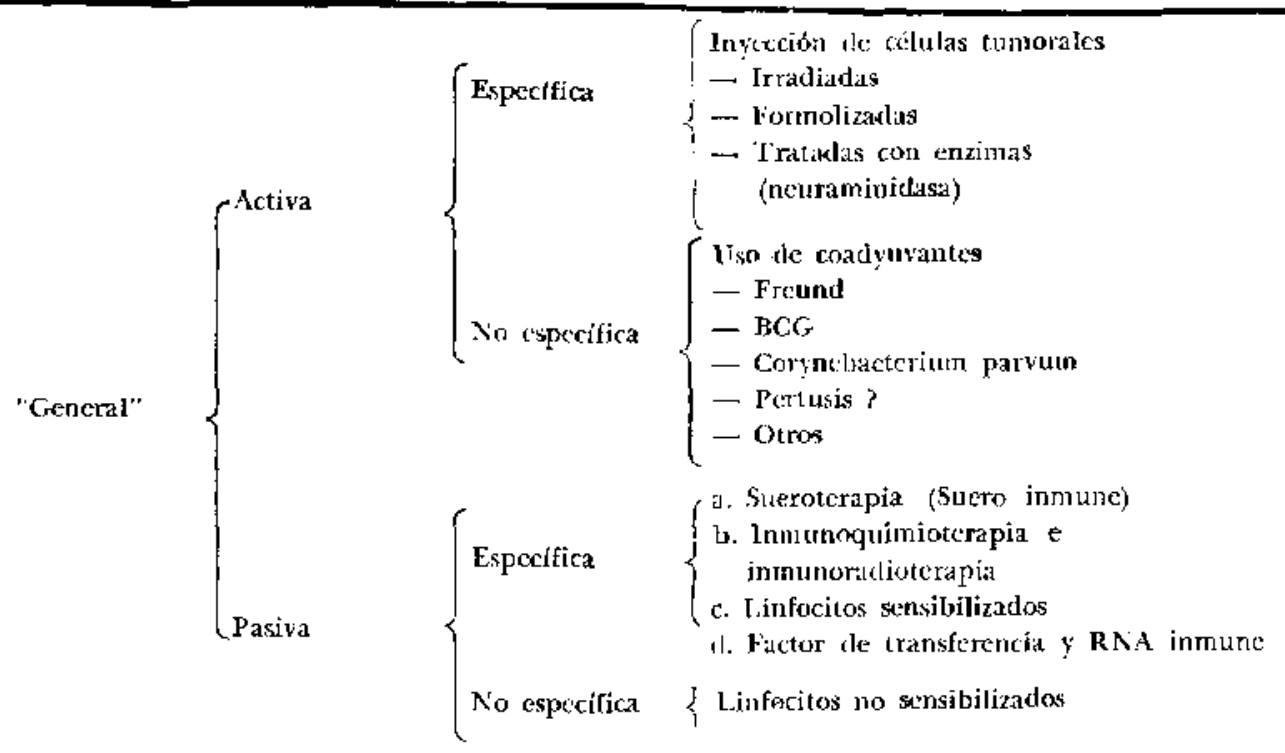

"Locitl" $\quad$ Inyección Incal (intanmoral) dre suhstancias que pro. $\{$ vocan reacción de Jipersensibilitlad. 
retículo endotelial $(42,13)$. Este campo es amplio y promisorio. Las razones por las cuilles estas substancias exaltan la inmunidad no se conocen bien y está actualnente bajo intcnso esuludio. Sin embargo, algunos hechos sa hitn comprolado: inyectadis localmente, intratumoral (caso de melanonis), provocan al parecer una reacción de hipersensibilidad retardada local, Iá cual destruye secundariamente al tumor (39). En la experimentación animal e inycctadis por via general, se han revelado como potentes estimulaclores del sistema reticular con probalble producción de macró. fagos agresores específicos y no especificos. Las stobstancias comúnmente más usadas son: BCi. (10) y extractos de corinebacterium par. vum (14). El uso de vacuna pertusis no la dado los resultados esperados. Varias otmas sulbstancias están en cstudio; cxtractos de Nocarclia, Statolon (derivado de ana varieclad the penicillium) (45) yotros.

El eferto de estas substancias en las immuniclades linfocitoceluliares y lumorales es menos clara y dificil de explicar.

\section{c. Immmolerapia general, pasion, rsperifica:}

Consiste en inyectas al lutésperl, elementos antiumoriles proformados, tales como sncro liperinnume, linfocitos sensibilizados y cito. tosicom, etc. Su utilidad teórica mayor radiraríat en su poder citorreductor del tumor. En ci terreno teórico también su efecto no scría permarente por cuanto no induciría un estado de immunidal que habilite al hućsped para combatir en forma cluraclera a la neoplasia. Los resultados con sueroterapia han sido conflictivos ya que no pocas veces st? provocó estimulación del crecimiento tunsoral, tal ve por la adminis:ración de anticuerpos bloquenclotes o favorecedores (progresores) (99). Lat ntilización de linfocitos sensibilizados hat tenido resultados más exitosos, sea admistránclolos por via sreneral o local, como los demuestran algunas cxperiencias con el melanoma maligno (99). Recientemente se Iran hecho experiencias más sofisticadas con derivatos linfocitarios de pacientes portadores de cancer. Je los linforitos the estats porsonlas se extraen substancias de bajo pexo molecular (el lactor de transferencia y el ARN inmunc) que a] ser inyectadas a otro paciente con tumor, lc transficcen la información necesaria al sistema linfocitario slel receptor para que respondit positivamente frente a ta neoplasia (10). Esla modalidad de inmunoterapia se está estudian. do intenstmente en la actualiclad. Otra posibilidad ale inmunoterapia pasiva cs la inmunoquimioterapia y lit immunorradioterapia. En ambos casos se trata de acoplar a fos anticuerpos antitumores, agentes citóóxicos químicos en el primer caso, o elementos radionctivos en el segundo. Seria una manera de dirigir y concentrar elementos destructivos on el tumor mismo. Estat posibilidad, de gran interés teóricoprítctico, es todarit de indole experi. mentirl $(47)$.

\section{(1. Inmwnoterapia grmeral, pastutt, no especifica:}

EI uso de linfocitos no sensibilizados y recolec'cakos drenancho canales línfáticos mayores, juede sar incluido en este rubro (48). Los resultaclos han sido poco favoralbles. También puesle incluirse aquí el uso de substancias que atumentan la producción de interferion, Ja co. nocida substancia antiviral generacla por tas rélulas infestadas con virus. Se piensa que por cate medio se logrisía impedir la acción de virus oncogénicos y con ello la cventual rein"Iucción de novo de la maligniclatd (19). En animales de experimentación se han usado: "u polimero dé ácido inosínico y citidílico (Poli-I y Poli-C) (50), el Statolon (derivado de homgo penicillium) (45) y la infestación de los tumores con virus no oncogénico. Por último. se lian descubicrto substancias quimicas relativamente simples, que restaurarian inmuvidales deficientes, como el levamisole (un agente usado como vermífugo en animales y en el lionbre) cuyo uso ha provocado resulados divergentes. Esta droga aumentaria la inmunidlad celular deficiente hasta un nivel normal, pero no más allá. Se requiere mayor experiencia con esta droga para establecer claramente sus indicaciones (51).

c. Inmunoterapia local:

Como su nombre Io indica, la aplicación local cle agentes antitumorales potria beneficiar al 
paciente. Locitmente se han inyectado BCG, corindycterium paryum y dinitroclonobenceno. Se produce in situ una reacción de lipersensibilidad reardada, la cual destruye el tunutor. La inyección local de linfocitos sensibili. daclos también ha sido eficaz. En toclo caso este rooto de inmunoterapia sólo es aplicable a cscaso núuncro de cúnceres (molanoma y cíncer cutáneo, primitivo o metastásicos) y no constituye un medio terapéutico de uso extenso (32).

Obscruacion final: Por el momento se debe cnfalizar que la inmunolerapia está aún en fase experimental y no onstituye un medio terapéutico de cheacia global y siempre compwbarla. En rodo ciso, constituye un elemento atuxiliar de tratamicnto cuyas modalidades. lipo. vías de amonistración, continuidad, tiempo de aplicatión y control está por dieserminarse.

El datamien:o de los tumores maligno; radica fundamentalmente en los procedinientos tradicionales tales como da extippación quirúgica, us de raliotcrapia y quimioterapia. Gran pate tle las expcriencias con tratamientos inmumológicos está basada en manipulacio. nes con animales de laboratorio, con trasplientes tumorales $y$ en condiciones que poro sc parcen at lo que se observa en clínica humana. That reconocerse si que cstats experienci is son en extreno yaliosus ya que han abierto un ampo muy promisorio en el control de las malignicladcs, en su iratamiento y probablemente tambien on el aspecto preventivo. Por otra jarte, estas experiencias han permitido un conocimiento más acabado de las interreacrioncs immunológicas en general que se exlicnde a otros campos de la inmunología.

Las experiencias en animales parecen indi. ar que un hucsped eliminaría inmunológicamente un tumos, solamente culudo éste se hat ralucido a menos ale $10^{-1}$ células malignas residartes. Muchos piensin que en clínica liumana esta cifra podría ser de $10^{5}$ o menos células. Tal tamaño es clínicamente casi indetectable (monos de l centínetro cúbico), de tal nodo que seria imperativo retucir un tumor, por los medios tradicionales, Jasta tun sprido míxi. mo para poner al orgenismo en rondiciones de climinar inmunológicamentc al tumor.

Fs importante también considerar el cslitdo innunológico del paciente portador de cáncer, amalizandolo tanto en forma previa a todo rratamiento como durante la acción de los tratamientos tradicionales, ya que éstos son fuertemente inmuno-suprcsores, especithmente lat ratioterapia y la quimioxterapia. Si la inmuniclat se encuentra deptimida, habrian razoncs de peso para influir con inmunoterapia esta deficiencia $y$ tratar de restauriula. Se sabe de solara que los pacientes con buena inmuniclad lienen mejor fronóstico que los que no lis tienen. Lina vez lograda la restauración inmunitaria o conjuntanente con ella, convendríal ulilizar algún medio de obtener innunidat permancnte por molio de inmumo:erapia espocilica, para evitit una posible recrudecen. cia cle la neoplasia.

De torlas mancras. estas son consideraciones más bien teóricas que de elicacia probakla. Mudio quedia por ensayar y valorar, antes de sentar bases definiclas en torno a este problemit.

\section{RFFFRE.VCIAS}

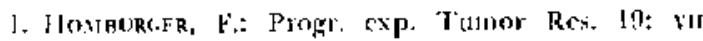
(Ka)g(r. Basel), 1974.

2. Surtuds, C. M.: Cancer Res. 28: 1.433-1.440, 1968

3. MIortor, J). L.: Surgeny 71: 69.79, 1973.

1. Eurkon T. C. and Cole W. H.: Amn. Sarg. 1f4: $360,195 \%$

5. Crerklf, (i. A.: Medical Oncology (B)ackwall Scicenlific Publicaltios) Pp. $19.39,1975$.

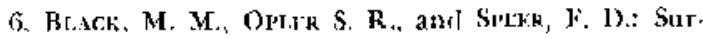
fery, 6;тtuc. Obstr., 98: 725, 1954.

7. Fikkow, Y. I: Blood, 30: 388, 1967.

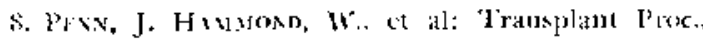
I: 106, 1969 .

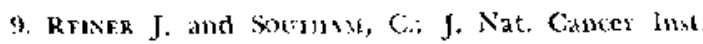
38: 753,1967 .

10. Matmeren, R. A. el al.; Proc. Soc. Exp. Biol. Med, 79: $484 \cdot 488,3 ! 152$.

11. II:NC, P. B.: I'rogr. Mtal. Virul. 14: 1-35, 1952.

10. Enynar, E, M. et al: Pjoc, Aner, Mss. Cances Res., 2.: 2 2., 1970 . 
13. KAY, H. E. M.: Clinical Aspccts of Inmunology (Blackwell Scientific Publications, Oxford) pp. $629-647,1975$.

14. O'Covor, G. T.: Aner. J. Med.. 48; 279-280, 1970.

15. Currif, Gr A. and Bacshawe, K. D: Brit. J. Cancer, 23: 191,1969 .

16. Herberkina, R, B. ct al, J. Nat, Cancet list., 46: 391,1971

17. Poli.ak, s. et al.: Int, J. Cancer, 9: \$16, 1972.

18. Ginseure; H.: lmmunology, 14: 621, 1968.

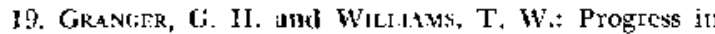
Inmunology p. 437, in Anos Is. Acadumic Press, New York and london (197)

20. LawrencF, E. S. athd LANov, M.: Mediators ot cellular immunity. Acaderuic Press. New York and Louclon, 1900 .

21. EYans, R, and Alexanner, P.: Nature, 286: 16d. 1972 .


18: 260,1964 .

23. Mircher.t. M, S. Ct al.: Ann. Intern. Mcd., 7 (j: 393 , 1973.

24. Grashwin, M. E. and Steingfre, H. M.: Lancet, 2: J.174-1.176, 1973 .

25. Kirkwooly, J. M. and Cirshon, K. K.: Progr. exp. Turnor Res, J9: 157-lot (Karger, Bascl), 1974

26. CAstr, A. E.: Cancet Res., 1: 194, 1941.

2i. Kaliss, N. atd Molomet, N.: Cancer Res, 12: 110, 1956.

28. Kaliss, N. and Kandutsch, A. A. Hroc, Soc, exp. Biol. Med., 91: 118, 1956.

29. Helistrok 1, I, atul Hellstrofa, K. E,: J. Relicaloendotheliac sox: 10: 131, 197!,

30. Cruse, J. M. et al, Progr. exp. Tumor Res., 19: 1) 0.156 (Katger, Bascl) , 1974.

31. Mrtchisos, N. A.: Clinical Aspects of Imununology, pp. 599-62] (Blackwell Scientific Publications, Oxford) , $19 \%$.

32. Atrextioer, P. et al.: Proc. Roy. Soc, Lontl, IB. 1974: 237,1967

33. OID, L. J. et al.: J. Exp. Mcd., 127: 523, 1968.

34. Tavlor, R. B. et al: Nature New. Biol, 293: 225, 1971 .

35, Bufrotict, W, S.: Nat. Cincer Inst. Honogt., 38 : 9).107, 1973.

36. RYTön.A, T.: Irrit. Y, Haenat. 29: 141, 197g.

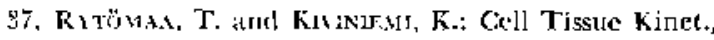
1: 329.1968.

38. Rytöman, 'T. and Krviniz:1I, K.: Cell Tissuc Kinct, l: 341,1968 .

90. MavLlorr, $(;$ et a].; Progr. exp. Tunor Res., 19: 2920.252 (Karger, Basel), 1974

40. Matití, G., et al.: Lancét 1: 697.690, 1969.

41. Matifi, G. et il,: Rev, Eur. Etud. Cín. Biol., 1f: $216-224,1971$.

42. Cis, I. J. ce al.: Cancer Res., 2l: 1281-1300. 1961,

43. OLd, L. J. ct al.: Nature, Itonton, 184: $291-292$. 1959 .

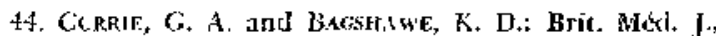
1: $541-541,1970$.

45. Wifelock, E. l., et al: Progr. exp. Tumor Res. 19: 960 )-389 (Karger, Basel), 1974 .

46. PILcir. Y. H.: Ann, Inter. Ned, 77: 43L-451, 1972.

47. Cinose, '1. et al.: Jirit. Med. J., 3: 495, 197:

48. Moore, C. E and Gerncr, R. E.: Ann. Surg, 17\%: $733-7 \$ 9,1970$

19. Crossfr. T., al all: Anח, N, Y. Acar. Sci., 173; 694$7 \mathbf{6}] 9 ;$,

50. Lexy, H. I3., law I. W., and Kabson, A. S.: Proc Nat. Acad, Sci., Usi, 62: 357-361, 1969.

5l. KLak, J. I..: Science, 191 1.9.75), 1975. 